RU Лексико-грамматические средства выражения интенсивности речевого воздействия в русско- и англоязычных социально-политических дебатах

\author{
Кулабухов Н. В.
}

\begin{abstract}
Аннотация. Цель исследования - выявить функциональный потенциал разноуровневых средств выражения интенсивности речевого воздействия, используемых участниками русско- и англоязычных социально-политических дебатов (СПД). В статье представлен подробный анализ лексико-морфологических средств, интенсифицирующих речевое воздействие высказываний участников СПД. Научная новизна исследования заключается в функциональном подходе к анализу языковых средств выражения интенсивности воздействия в речи политиков - участников СПД. В результате доказано, что участники СПД стремятся оказать воздействие на публику, обращая ее внимание в основном на статические признаки и качества предметов и явлений, положение вещей в данный момент.
\end{abstract}

\title{
EN Lexical and Grammatical Means for Expressing Speech Influence Intensity in the Russian-Language and English-Language Socio-Political Debates
}

\author{
Kulabukhov N. V.
}

\begin{abstract}
The purpose of the study is to identify the functional potential of different-level means for expressing intensity of speech influence used by participants of the Russian-language and English-language socio-political debates (SPD). The article presents a detailed analysis of the lexical and morphological means that intensify speech influence of the statements made by SPD participants. Scientific novelty of the study lies in taking the functional approach to analysing linguistic means for expressing influence intensity in the speech of politicians participating in SPD. As a result, it is proved that SPD participants strive to influence the public, drawing its attention mainly to static attributes and qualities of objects and phenomena, the state of things at the moment.
\end{abstract}

\section{Введение}

Актуальность темы исследования обусловлена отсутствием на настоящий момент возможности измерения интенсивности и необходимостью проведения анализа средств ее выражения в речи политиков, участвующих в социально-политических дебатах.

Для достижения указанной цели исследования необходимо решить следующие задачи: во-первых, рассмотреть интенсивность как реляционное понятие, то есть в ее связи с понятием предиката; во-вторых, описать типы предикатов с точки зрения функционального подхода; в-третьих, определить и охарактеризовать основные языковые средства выражения интенсивности; в-четвертых, провести анализ языковых средств выражения интенсивности в высказываниях участников СПД с целью выявления лексико-грамматических особенностей осуществления речевого воздействия в функциональном аспекте.

Для описания и анализа языковых средств выражения интенсивности речевого воздействия в высказываниях участников СПД в статье применяются следующие методы исследования: описательный метод, метод сплошной выборки, лексико-грамматический анализ, сравнительный метод по определенным критериям, количественный анализ.

Теоретической базой исследования послужили труды И. И. Туранского, И. Ю. Кутейш, С. Е. Родионовой, И. А. Стернина в области изучения категории интенсивности и речевого воздействия, а также работа зарубежного ученого У. Чейфа в области изучения понятия предиката. 
Практическая значимость исследования заключается в том, что полученные результаты могут быть использованы в вузовских курсах по стилистике, когнитивной лингвистике и теории интенсивности речевого воздействия.

\section{Ключевые понятия исследования}

Как видно из названия настоящей статьи, основными для нашего исследования выступают понятия СПД, речевого воздействия и интенсивности.

Под СПД мы будем понимать жанр социально-политического дискурса, в котором политики дискутируют по вопросам социально-бытовой сферы, пользуясь при этом аргументированными высказываниями, ограниченными рамками определенного контекста.

Под речевым воздействием понимается ситуация, когда говорящий воздействует на одного или нескольких человек, применяя для этого собственную речь и невербальные средства, которые ее сопровождают, чтобы поставленная им цель была достигнута [6].

Многие исследователи (И. Ю. Кутейш [4], С. Е. Родионова [5], И. И. Туранский [8], Е. И. Шейгал [10] и др.), изучавшие понятие интенсивности (от лат. intendere - напрягать), связывают его с мерой количества, количественной характеристикой признака. Таким образом, интенсивность - это категория меры, которая шире категории количества, поскольку может выражаться: а) в количественных (точных) параметрах («Он на 100\% патриот») и б) в неколичественных, относительных параметрах («Этот вариант несравнимо лучше, чем то, что вы предложили в прошлый раз»). Поэтому мы в своем исследовании будем понимать интенсивность как категорию, в основе которой лежит количественное изменение признака, выступающую мерой речевоздействующего потенциала и располагающую собственным набором средств выражения [3].

Следует отметить, что интенсивность в нашей работе рассматривается в опоре на ее потенциальные возможности увеличивать речевое воздействие, то есть мы не исследуем перлокутивный эффект, результат речевоздействия. Поэтому мы и понимаем интенсивность как меру именно речевоздействующего потенциала.

\section{Предикатоцентрический подход У. Чейфа}

На данный момент нет возможности для установления меры (степени) интенсивности речевоздействия высказываний участников СПД, поскольку для этого необходимы специальные проверенные методики, которые в настоящее время отсутствуют. Имеющиеся точные методы охватывают области языка, не относящиеся напрямую к социально-политическому дискурсу. Так, программа Diatone исследует фоносемантику слова, ВААЛ - фоносемантику текста, Пси-офис - подсознательные компоненты речи; так или иначе, они направлены на измерение суггестии, что не входит в задачи нашего исследования. Но можно изучать многообразие типов интенсивности в дискурсе. Интенсивность является реляционным понятием (интенсивность ЧЕГО-ТО), то есть связанным с понятием признака/качества. Поэтому на первый план выходит понятие интенсивности признака: действия, процесса, свойства, состояния, отношения и т.п., то есть мы в данном случае говорим об интенсивности предиката, поскольку рассмотрение свойств некоего предмета или явления (феномена) подразумевает приобретение этим предметом или явлением предикатных характеристик, то есть характеристик, описывающих его признаки и качества. Именно поэтому мы и говорим о том, что понятие интенсивности связано с понятием предиката. Иначе говоря, рассматривая интенсивность, мы неизбежно рассматриваем предикат. Конечно, речь в данном случае идет не о сказуемом предложения, а о предикатных, или, по-иному, непредметных знаках.

Предикат может выражаться при помощи различных частей речи (существительное, прилагательное, глагол) и словосочетаний. Признак может рассматриваться с точки зрения синтаксиса - для разных членов предложения: в функции подлежащего, сказуемого, определения и т.д. В функции подлежащего и определения предикат является предикатным словом (свернутой пропозицией). Поэтому можно рассматривать признаки по группам: признаки-подлежащие, признаки-сказуемые, признаки-определения и т.д.

По-видимому, адекватный анализ предикатов невозможен вне их функционального аспекта. Мы будем придерживаться предикатоцентрической классификации У. Чейфа, в основе которой лежит тот факт, что состояния и события противопоставляются друг другу, причем в состояния входят положения и качества [9, с. 114]. У. Чейф рассматривает четыре основных семантических типа предикатов: Состояние (The wood is dry / Дерево сухое), Процесс (The wood dried / Дерево сохло), Действие-Процесс (Michael dried the wood / Maйкл высушил дерево) и Действие (Michael ran / Майкл бежал) (последние три относятся к событиям).

Характерный признак Состояния - статичность. Предикат сопровождается существительным, которое является «патиентом» (объектом воздействия) (the wood).

Характерный признак Процесса - отсутствие статичности. Предикат указывает на то, что «патиент» (the wood) изменил свое состояние.

Характерный признак Действия-Процесса - воздействие. С одной стороны, предикат обозначает действие, совершаемое его «агентом» (Michael). С другой стороны, он служит причиной изменения состояния «патиента» (the wood).

Основной признак Действия - нетранзитивная активность. Для него характерно наличие «агента» (Michael) и отсутствие «патиента» [Там же, с. 116-121]. 
Эти типы могут переходить друг в друга при помощи деривационных процессов [1].

Тем самым мы принимаем, что в языковом аспекте интенсивность признака проецируется на его семантику.

\section{Выделение и характеристика языковых средств выражения интенсивности}

Иногда интенсивность путают с экспрессивностью, но это разные категории, поскольку интенсивность шире экспрессивности. Она может выражаться экспрессивно, например, особыми синтаксическими конструкциями типа инверсии или эллипсиса, а также фонацией (особыми тональными рисунками, громкостью, темпом, высотой голоса). Также интенсивность бывает языковой и речевой. В качестве способов реализации языковой интенсивности выступают различные языковые средства: семантико-синтаксические, лексические, морфологические и т.п. Способами реализации речевой интенсивности являются разнообразные речевые средства: стратегии, тактики, аргументативный рисунок высказываний и т.п. Речевые средства интенсификации (усиления) высказывания зависят от конкретных дискурсивных условий общения.

При рассмотрении источников по языковым средствам выражения интенсивности, изученным в наиболее значимых подходах С. Е. Родионовой [5] и И. И. Туранским [8], выявлено, что авторы выделяют одинаковые способы интенсификации высказывания. Разница состоит в том, что С. Е. Родионова делит эти способы на более важные и менее важные, где за основу берется частотность употребления этих средств, чего нет у И. И. Туранского. Также есть разница в содержании средств на каждом уровне. Отсюда можно сделать вывод, что классификации языковых средств выражения интенсивности С. Е. Родионовой и И. И. Туранского касаются разных аспектов, но в целом не имеют рассогласований друг с другом. Поэтому нам показалась вполне осуществимой идея обобщить классификации С. Е. Родионовой и И. И. Туранского, таким образом представив единую классификацию языковых средств выражения интенсивности.

В результате такого объединения можно считать, что языковыми средствами выражения интенсивности являются: 1) лексические средства, которые реализуются существительными, прилагательными и глаголами интенсифицирующего содержания (значения), наречиями-интенсивами, кванторными словами и компаративными фразеологическими единицами; 2) морфологические средства, куда можно включить превосходную степень прилагательных и эмфатический усилитель dо в английском языке; 3) словообразовательные средства, в качестве которых выступают аффиксация и словосложение; 4) синтаксические средства, к каковым можно отнести повторы, восклицательные предложения, особые синтаксические конструкции и сравнительные обороты; 5) графические средства, реализуемые многократным написанием букв (удлиненным произношением ударного звука в речи), выделением курсивом, написанием заглавными буквами; использованием дефиса, разбивающего слово или предложение на части.

И. Ю. Кутейш [4] выделила систему видов оппозиций категории интенсивности: бинарные (estimate overestimate), градуальные (усилительные наречия, степени сравнения прилагательных) и эквиполентные (синонимические ряды). Мы сочли правомерным также использовать данную систему при анализе языковых средств выражения интенсивности.

Немаловажную роль в характеристике лексико-грамматических средств интенсивности играет их коннотация. Так, встречаются пейоративные (с отрицательной коннотацией) и мелиоративные (с положительной коннотацией) интенсивы.

\section{Анализ лексико-грамматических средств выражения интенсивности в СПД}

Материалом для анализа языковых средств выражения интенсивности послужили русскоязычные дебаты кандидатов на пост мэра Москвы от 16.08.2013 [7] и англоязычные дебаты лидеров оппозиционных партий Великобритании от 16.04.2015 [11].

Выбор именно указанных дебатов для анализа обусловлен соображением о том, что и те, и другие дебаты имеют близкую коммуникативную ситуацию и предметную область обсуждения. Также приблизительно одинаковыми являются временные рамки проведения этих дебатов.

Анализ лексико-грамматических средств выражения интенсивности проводится с точки зрения следующих критериев: 1) коннотации; 2) вида оппозиции; 3) функционального аспекта; 4) синтаксического аспекта. Начнем разбор с лексических средств выражения интенсивности.

Итак, в высказываниях участников русско- и англоязычных СПД в качестве лексических средств выражения интенсивности были обнаружены интенсифицирующие прилагательные, наречия-интенсивы и так называемые сигналы «тотальности», упоминаемые О. С. Иссерс [2]. Рассмотрим примеры.

(1) Иван Мельников: Начну с того, что нынешним московским чиновникам выгодно иметь миллионы нелегальных мигрантов как дешевую рабочую силу и из этого качать баснословную прибыль.

Natalie Bennett: ...people aren't paid enough money to live on, they're indeed stacking up the debts just to meet their basic costs. The cost of housing is enormous. / Натали Беннет: ...людям не платят достаточно денег на проживание, они действительно накапливают долги только для того, чтобы покрыть свои основные расходы. Стоимость жилья огромна.

В данных примерах использованы интенсифицирующие прилагательные баснословную и еnormous, имеющие одно и то же значение «очень большой». Указанные средства интенсивности обладают следующими характеристиками:

1. Мелиоративные интенсивы (с положительной коннотацией). 
2. Вид оппозиции - эквиполентный.

3. Функциональный аспект. Словосочетание баснословную прибыль состоит из именного элемента «прибыль» и предикативного элемента «баснословную», который, по классификации У. Чейфа [9], относится к предикатам состояния, поскольку выражает признак/качество прибыли. Высказывание The cost of housing is enormous состоит из именного элемента "the cost of housing" и предикативного элемента “is enormous", который также является предикатом состояния, выражая признак/качество стоимости жилья. Оба прилагательных (баснословную и enormous) интенсифицируют (усиливают) свое общее значение «очень большой» имплицитно, поскольку уже содержат в себе сему интенсивности. Поэтому в приведенных примерах мы имеем интенсивность состояния.

4. Синтаксический аспект. Предикат баснословную выражен прилагательным, поэтому с точки зрения синтаксиса данный признак относится к группе признаков-определений. Предикат is enormous выражен глаголом-связкой с полным прилагательным, поэтому с точки зрения синтаксиса данный признак относится к группе признаков-сказуемых, так как enormous является частью именного сказуемого.

В анализируемых дебатах обнаружены еще случаи интенсивности состояния в виде интенсифицирующих прилагательных: грандиозного, мошенническими, гигантские, колоссальная, ехтrете 'чрезмерный', huge 'огромный’ и др. В русскоязычных СПД были также обнаружены случаи использования интенсифицирующих глаголов (обдирают, благоухать) и прилагательных в кванторном значении (целые, каждого, любого, полную).

(2) Иван Мельников: С этим чрезвычайно тяжелая ситуация, и главная причина в том, что антиэкологическое мышление чиновников, попытка выбить прибыль с каждого сантиметра московской земли, она приводит к тому, что безбожно все вырубается, вытаптывается.

Natalie Bennett: The whole way our housing market has work has utterly skewed our eсопоту. / Натали Беннет: То, как работает наш рынок жилья, полностью исказило нашу экономику.

В данных примерах использованы наречия-интенсивы чрезвычайно (тяжелая) и безбожно (вырубается, вытаптывается), а также utterly (skewed). Указанные средства интенсивности обладают следующими характеристиками:

1. Пейоративные интенсивы (в сочетании с прилагательным тяжелая и глаголами вырубается, вытаптывается и skewed).

2. Вид оппозиции - градуальный.

3. Функциональный аспект. Словосочетание чрезвычайно тяжелая ситуация состоит из именного элемента «ситуация» и предикативного элемента «чрезвычайно тяжелая», который является предикатом состояния, поскольку выражает признак/качество ситуации. При этом чрезвычайно является признаком прилагательного тяжелая и интенсифицирует (усиливает) его значение эксплицитно, указывая на чрезмерную степень признака, то есть на то, что данное свойство представлено в большей степени, чем нужно. Поэтому в данном примере мы имеем интенсивность признака состояния. Высказывание безбожно всё вырубается, вытаптывается состоит из именного элемента «всё» и предикативного элемента «безбожно вырубается, вытаптывается», который является предикатом процесса, выражая изменение состояния «патиента» (всё). Безбожно при этом выступает признаком глаголов вырубается, вытаптывается, эксплицитно интенсифицируя (усиливая) их значение за счет того, что также указывает на чрезмерную степень процессов вырубания и вытаптывания. Поэтому здесь уже будет интенсивность признака процесса. Высказывание The whole way... has utterly skewed our econoту состоит из именного элемента “the whole way” и предикативного элемента "has utterly skewed our economy”, который является предикатом действия-процесса, выражая воздействие «агента» (the whole way) на «патиента» (our economy). Utterly является признаком глагола skewed и эксплицитно интенсифицирует его значение, также указывая на чрезмерную степень воздействия на экономику. Поэтому в данном примере представлена уже интенсивность признака действия-процесса.

4. Синтаксический аспект. Предикат чрезвычайно тяжелая выражен наречием с последующим прилагательным, а предикат безбожно вырубается выражен наречием с последующим глаголом, поэтому с точки зрения синтаксиса данные признаки относятся к группе признаков-обстоятельств меры и степени. Предикат has utterly skewed выражен наречием с последующим глаголом, поэтому с точки зрения синтаксиса данный признак относится к группе признаков-обстоятельств.

В анализируемых СПД были обнаружены и другие наречия-интенсивы, такие как очень, значительно, крайне, vеry 'очень', тисһ 'гораздо', deерly 'глубоко', dangerously 'опасно', disastrously 'катастрофически'. Наречия-интенсивы чрезвычайно, безбожно, значительно и крайне являются гипонимами по отношению к наречию-интенсиву очень.

(3) Михаил Дегтярев: ...вернем все надбавки пенсионерам, а всем бюджетникам... мы повысим зарплаты...

Natalie Bennett: Students are leaving with $£ 44,000$ worth of debt on average, $73 \%$ of them will never pay it off. I Натали Беннет: Студенты остаются с долгом в среднем на 44000 фунтов стерлингов, 73\% из них никогда не выплатят его.

В данных примерах используются определительное местоимение все и отрицательное местоимение never, выступающие в качестве сигнала «тотальности», способствующего распространению явления с помощью преувеличения, чтобы представить общее положение дел, которые обладают следующими характеристиками:

1. Мелиоративные интенсивы.

2. Вид оппозиции - эквиполентный.

3. Функциональный аспект. Вначале уточним, что мы не рассматриваем полностью предложение (с глаголами) в русскоязычном примере, а берем только отдельные словосочетания, поскольку только в них 
содержатся компоненты интенсивности (все, всем), а не в действиях, выраженных глаголами. Итак, словосочетания все надбавки и всем бюджетникам состоят из именных элементов «надбавки» и «бюджетникам» и предикативных элементов «все» и «всем», которые являются предикатами состояния, выражая количество надбавок и бюджетников, а также интенсифицируя это количество с помощью преувеличения. Поэтому в данном примере мы можем наблюдать интенсивность состояния. Словосочетание 73\% of them will never pay it off состоит из именного элемента “73\% of them” и предикативного элемента "will never pay it off”, который является предикатом действия-процесса, так как выражает воздействие «агента» (73\% of them) на «патиента» (it (debt)). Never выступает в качестве признака глагола рау и эксплицитно интенсифицирует его значение, только в сторону уменьшения, так как указывает на полное отсутствие выполнения данного действия. Поэтому здесь представлена интенсивность признака действия-процесса.

4. Синтаксический аспект. Предикаты выражены определительным и отрицательным местоимениями, поэтому с точки зрения синтаксиса данные признаки относятся к группе признаков-определений и группе признаков - обстоятельств времени, соответственно.

В анализируемых дебатах обнаружено еще три случая использования определительного местоимения все (всю информацию, во всех парках, все это), один случай использования отрицательного местоимения ничего (ничего нового), а также использование наречия always (всегда) (the SNP will always stand up for... / ШНП всегда будет защищать...), выступающих в качестве сигналов «тотальности».

В высказываниях участников русско- и англоязычных СПД в качестве морфологических средств выражения интенсивности были выявлены_прилагательные в превосходной степени. В англоязычных СПД помимо превосходной степени прилагательных наличествует еще и эмфатический усилитель do. Кроме того, были обнаружены перфектные формы и формы продолженного вида, но эти формы не влияют на создание интенсивности. Рассмотрим примеры.

(1) Ведущий: Вы заявляете... что сделаете Москву-реку крупнейшей рекреационной зоной в Москве...

Nicola Sturgeon: I think housing is possibly one of the biggest issues in this election campaign. / Никола Стерджен: Я думаю, что жилье - это, возможно, одна из самых больших проблем в этой избирательной кампании.

В данных примерах использованы прилагательные в превосходной степени крупнейшей и the biggest, которые обладают следующими характеристиками:

1. Мелиоративные интенсивы.

2. Вид оппозиции - градуальный.

3. Функциональный аспект. Словосочетания крупнейшей зоной и the biggest issues состоят из именных элементов «зоной» и “issues” и предикативных элементов «крупнейшей» и “the biggest”, которые являются предикатами состояния, поскольку выражают признаки/качества именных элементов. Форма суперлатива интенсифицирует общее значение обоих прилагательных «очень большой». Поэтому здесь представлена интенсивность состояния.

4. Синтаксический аспект. Предикаты выражены прилагательными в превосходной степени, поэтому с точки зрения синтаксиса данные признаки относятся к группе признаков-определений.

(2) Nigel Farage: Well, our sums do add up, and very interestingly, Ed... / Найджел Фараж: Ну, наши суммы всё же складываются, и очень интересно, Эд...

Ed Miliband: And I do say to some people on the stage tonight, let's not pretend there is no difference between me and David Cameron... / Эд Милибанд: И я действительно говорю некоторым людям на сцене сегодня вечером, давайте не будем притворяться, что между мной и Дэвидом Кэмероном нет разницы...

В данных примерах использован эмфатический усилитель do, который обладает следующими характеристиками:

1. Функциональный аспект. Высказывание our sums do add up состоит из именного элемента “our sums” и предикативного элемента “do add up”. Высказывание I do say состоит из именного элемента “I” и предикативного элемента “do say”. Предикативные элементы в обоих примерах являются предикатами действия, поскольку там наличествует «агент» (our sums, I) и отсутствует «патиент», то есть налицо нетранзитивная активность. В обоих высказываниях использован вспомогательный глагол do, несмотря на то, что перед нами утвердительные предложения. Такое употребление превращает do в эмфатический усилитель, который интенсифицирует действия, выраженные глаголами add up и say. Поэтому здесь мы наблюдаем интенсивность действия.

2. Синтаксический аспект. Предикаты выражены глаголами, поэтому с точки зрения синтаксиса данные признаки относятся к группе признаков-сказуемых.

В анализируемых СПД обнаружены еще случаи использования превосходной степени прилагательного (тяжелейшее, самые лучшие (морфолого-синтаксическое средство), самый большой, самых активных, самых грязных, самые главные, the worst 'худший', the most important 'самый важный', the mоst vulnerable 'самый уязвимый') и эмфатического усилителя do (does want to tackle / действительно хочет взяться за и do want to deal with / действительно хотим иметь дело с).

Итак, анализ лексико-грамматических средств выражения интенсивности в речи участников русско- и англоязычных социально-политических дебатов показал наличие в их высказываниях около 40 лексических средств, а именно интенсифицирующих прилагательных и глаголов, а также наречий-интенсивов; 11 чисто морфологических средств, а именно превосходной степени прилагательных и эмфатического усилителя do в англоязычном материале. Также обнаружено 1 морфолого-синтаксическое средство, представляющее собой употребление элатива с дополнительным словом самый, что вызывает эффект удвоенной интенсификации (самые лучшие). Что касается функционального аспекта, в большинстве случаев в рассматриваемых СПД 
интенсифицируется состояние, то есть статический признак предмета. Случаев интенсификации действия, процесса, действия-процесса, то есть динамического признака предмета обнаружено гораздо меньше.

\section{Заключение}

Таким образом, мы приходим к следующим выводам. В большинстве случаев участники анализируемых СПД используют лексические средства выражения интенсивности - интенсифицирующие прилагательные и наречия-интенсивы. В меньшей степени используются морфологические средства выражения интенсивности. В основном это превосходная степень прилагательных, а также эмфатический усилитель do в англоязычном материале. С точки зрения функционального подхода, в основном в рассматриваемых СПД с помощью языковых средств выражения интенсивности интенсифицируются статические признаки предмета, выраженные прилагательными. В меньшей степени интенсифицируются динамические признаки предмета, выраженные глаголами.

Всё вышесказанное позволяет сделать вывод о том, что участники СПД пытаются оказать речевое воздействие на публику в большей степени за счет интенсификации состояния, положения дел в определенный момент, качества предметов и явлений.

Помимо средств, усиливающих речевое воздействие, в СПД, да и в любых дебатах вообще, непременно присутствуют средства, мешающие оказанию должного речевого воздействия. Поэтому перспективы дальнейшего исследования проблемы мы видим в выявлении и анализе лексико-морфологических средств снижения интенсивности речевоздействия.

\section{Источники | References}

1. Васильев Л. Г. Развитие синтаксической семантики в американском языкознании: дисс. ... к. филол. н. Калинин, 1983. 191 с.

2. Иссерс О. С. Коммуникативные стратегии и тактики русской речи. Изд-е 5-е. М.: ЛКИ, 2008. 288 с.

3. Кулабухов Н. В. Интенсивность речевого воздействия в социально-политических дебатах: автореф. дисс. ... к. филол. н. Тверь, 2018. 20 с.

4. Кутейш И. Ю. Категория интенсивности в современном английском языке (на материале литературы Великобритании и США ХХ века): дисс. ... к. филол. н. М., 1999. 244 с.

5. Родионова С. Е. Семантика интенсивности и ее выражение в современном русском языке // Проблемы функциональной грамматики. Полевые структуры / под ред. А. В. Бондарко. СПб.: Наука, 2005. С. 150-166.

6. Стернин И. А. Основы речевого воздействия. Воронеж: Истоки, 2012. 178 с.

7. Третий раунд дебатов кандидатов на пост мэра Москвы (полная версия) [Электронный ресурс]. URL: http://www.m24.ru/articles/23724 (дата обращения: 10.05.2021).

8. Туранский И. И. Средства интенсификации высказывания в английском языке: учебное пособие к спецкурсу для студентов педагогических институтов и факультетов иностранных языков. Куйбышев: Куйбышевский гос. пед. ин-т, 1987. 78 с.

9. Чейф У. Значение и структура языка. М.: Прогресс, 1975. 432 с.

10. Шейгал Е. И. Интенсивность как компонент семантики слова в современном английском языке: дисс. ... к. филол. н. М., 1981. 226 с.

11. Transcript of BBC 1, Opposition Parties Election Debate [Электронный pecypc]. URL: http://newswatch.co.uk/wp-content/uploads/2015/04/Transcript-of-BBC1-Opposition-Parties-Election-Debate.pdf (дата обращения: 10.05.2021).

\section{Информация об авторах | Author information}

RU Кулабухов Никита Владимирович ${ }^{1}$, к. филол. н.

${ }^{1}$ Калужский государственный университет имени К. Э. Циолковского

EN Kulabukhov Nikita Vladimirovich ${ }^{1}, \mathrm{PhD}$

${ }^{1}$ Tsiolkovsky Kaluga State University

${ }^{1}$ kulabukhoff.nikita@yandex.ru

\section{Информация о статье | About this article}

Дата поступления рукописи (received): 10.05.2021; опубликовано (published): 30.07.2021.

Ключевые слова (keywords): интенсивность; речевое воздействие; социально-политические дебаты; предикат; признак; intensity; speech influence; socio-political debates; predicate; attribute. 